\title{
Comunidade Indígena Nasa: Gênese histórica da construção de uma pedagogia própria
}

\author{
Nasa Indigenous Community: Historical genesis of the construction of its \\ own pedagogy
}

\author{
Fabian Mendoza \\ Mestre em Educação \\ Universidade do Estado de Mato Grosso - UNEMAT \\ Cáceres, MT - Brasil \\ almadepurada@yahoo.es \\ Rosângela Pereira de Oliveira \\ Doutora em Educação \\ Universidade Federal de Mato Grosso - UFMT \\ Cuiabá, MT - Brasil \\ esquilo.clio@gmail.com
}

Resumo: O texto apresenta uma síntese histórica da origem do Projeto de Educação Própria do povo indígena Nasa da Colômbia, através de quatro personagens, três individuais e um coletivo: La Cacica La Gaitana, Juan Tama, Manuel Quintín Lame e o Consejo Regional Indigena del Cauca - CRIC. A metodologia centra-se em uma revisão documental e bibliográfica de autores vinculados ao movimento indígena do Cauca. Na luta histórica pela recuperação de território, identidade e vida, os Nasa descobrem o valor fundamental da ancestralidade e da história como mestras e da educação como metodologia. A perspectiva decolonial associada às elaborações de Mignolo (2007), Dussel (1994) e Walsh (2013), é chave para dimensionar o sentido de sua luta diante das violências que invadem o seu território e realçar a transcendência de sua reconstituição epistemológica.

Palavras-chave: Comunidade indígena Nasa. Projeto de Educação Própria. Educação indígena. Decolonialidade.

Abstract: The text presents a historical synthesis of the origin of the Own Education Project of the indigenous Nasa people of Colombia, through four characters, three individual and one collective: La Cacica La Gaitana, Juan Tama, Manuel Quintín Lame and the Consejo Regional Indigena del Cauca - CRIC. The methodology focuses on a documentary and bibliographic review of authors linked to the Cauca indigenous movement. In the historic struggle for the recovery of territory, identity and life, Nasa people discover the fundamental value of ancestry and history as teachers and education as a methodology. The decolonial perspective associated with the elaborations of Mignolo (2007), Dussel (1994) and Walsh (2013), is key to dimensioning the meaning of its struggle in the face of the violence that invades its territory and highlighting the transcendence of its epistemological reconstruction.

Keywords: Nasa indigenous Community. Own Education Project. Indigenous education. Decoloniality.

Cite como

(ABNT NBR 6023:2018)

MENDOZA, Fabian; OLIVEIRA, Rosângela Pereira de. Comunidade Indígena Nasa: Gênese histórica da construção de uma pedagogia própria. Dialogia, São Paulo, n. 37, p. 1-15, e19790, jan./abr. 2021. Disponível em: https://doi.org/10.5585/dialogia.n37.19790.

American Psychological Association (APA)

Mendoza, F., \& Oliveira, R. P.(2021, jan./abr.). Comunidade Indígena Nasa: Gênese histórica da construção de uma pedagogia própria. Dialogia, São Paulo, 37, p. 1-15, e19790. https://doi.org/10.5585/dialogia.n37.19790. 


\section{Dialogia}

MENDOZA, Fabian; OLIVEIRA, Rosângela Pereira de. Comunidade Indígena Nasa: Gênese histórica da construção de uma pedagogia própria

Introdução

A comunidade indígena Nasa tem uma longa e significativa história de resistência no contexto colombiano e latino-americano. Esse processo de afirmação da identidade, a cultura e o território, é inseparável da articulação de um projeto de Educação Própria que possibilite a aquisição, transmissão, estudo e investigação da cultura e do conhecimento construído por essa comunidade ao longo dos séculos.

Este artigo trará à memória as quatro figuras mais emblemáticas dos mitos e tradições dos Nasa, os pilares fundamentais da resistência indígena e de seu projeto educacional. A primeira delas é La Cacica la Gaitana e situa-se a meados do século XVI, no momento da invasão e conquista espanhola da América. Dela conheceremos a sua transcendência como organizadora primigênia da resistência indígena nos Andes colombianos.

Depois, avançaremos até começos do século XVIII para descobrir o Cacique Juan Tama, dando realce a seu enfrentamento, sem armas, com as instituições do Império Espanhol na América e ao enfoque intercultural de seu legado.

Avançando no tempo iremos a 1915 onde nos aguarda a história de Manuel Quintín Lame, reativador da consciência indígena defensor de seus direitos e pedagogo.

Por fim, iremos a 1971 para destacar uma figura coletiva, o Consejo Regional Indígena del Cauca - CRIC, a primeira organização indígena colombiana com uma ampla agenda política e educacional que dará origem ao Projeto de Educação Própria do Povo Nasa.

A história dos Nasa é o relato da resistência aos poderes hegemônicos que têm ameaçado sua unidade, identidade e território. Consequentemente é uma bússola fundamental para o presente e o futuro, uma das mestras da comunidade por seu sentido didático e pedagógico. Nela testemunhamos a descoberta de sua criatividade política, plasmada na necessidade de manter o grupo coeso e encorajar aos mais novos a enfrentar os desafios de sua geração.

\section{Justificativa}

Escondidas, meio apagadas, à sombra das sociedades hegemônicas de cada região e país do continente, existem comunidades e experiências de organização das que apenas temos notícias. Ainda hoje padecem a marginalização das periferias territoriais, políticas, econômicas e epistemológicas aonde as disputas pelo poder das sociedades majoritárias as têm relegado.

A visibilização destas experiências possibilita leituras críticas da nossa cultura e evidencia as assimetrias que a atravessam, questionando nossa relação com o espaço, a 
natureza, os anciões, as mulheres, as crianças, a identidade e o pertencimento a uma comunidade.

Os Nasa, como povo, identidade, território e cultura indígena em reconstrução, apreenderam a ver sua história como um processo educativo. A memória, a tradição oral e as reelaborações contemporâneas de sua narrativa histórica compõem uma biblioteca, um laboratório, uma oficina onde repousam os registros das experiências de suas lutas. Esta afirmação epistemológica é uma ressignificação do seu conhecimento e seu saber ancestral.

A materialidade do projeto de Educação Própria do povo Nasa descansa, do ensino fundamental à formação dos professores, nos aprendizados cardinais conteúdos nessas memórias, tradições orais e narrativas históricas protagonizadas pelos personagens trazidos aqui neste escrito. Portanto, retomar essa trajetória germinal contribui a nos introduzir na compreensão da reconstrução cultural empreendido por esta comunidade e nos aporta reflexões e ensinamentos sobre o sentido dos nossos sistemas educacionais.

\section{Fundamentação teórica}

Este artigo explora as relações entre o pedagógico e o histórico numa perspectiva decolonial, opção epistemológica determinada pela profunda cicatriz deixada nas culturas indígenas pela colonização europeia (DUSSEL, 1994). O impacto sobre as comunidades nativas sobreviventes supôs a destruição, imediata ou paulatina, de sua cultura e território. Durante este período, identificado de maneira geral como Modernidade, a Europa alcançou uma centralidade política, econômica, cultural e epistemológica a partir da qual foram inferiorizadas as demais formas de relacionamento com o mundo, (MIGNOLO, 2007), arquitetando-se a Colonialidade do poder, do ser e do saber. Este princípio modelador das sociedades do nosso continente não foi significativamente alterado com a independência dos países latinoamericanos e sua fundação em Estados nacionais e repúblicas liberais.

Nesse contexto, história e resistência são sinônimos para o povo Nasa. Sua necessidade de coesão e organização dá-se em reposta aos poderes externos que pretendem usurpar ou vulnerar seu corpo, porque para ele seu território é um corpo, composto pelo mundo natural, humano e espiritual (PORTELA, 2018). Sendo assim, a própria história desta comunidade é a refutação à colonialidade das relações, isto é, aos efeitos negativos, opressores, destruidores, de toda investida colonizadora. Portanto, sua caminhada é uma experiência decolonial. 
A visão de uma educação própria surge com a pretensão de fortalecer o ciclo de três elos fundamentais que estrutura a recuperação da identidade indígena: a ancestralidade étnica como fator de diferença frente às identidades homogeneizantes da modernidade, sua relação mítica, histórica, ontológica com o território e os processos organizativos da comunidade como movimento social e político de resistência.

Desta maneira, na íntima relação entre ancestralidade, território e resistência, configuram-se práticas pedagógicas decoloniais que servem de metodologias, (WALSH, 2017), para as lutas políticas, ontológicas e epistêmicas.

Por último, ao enfrentar de maneira criativa as inúmeras violências colonizadoras que por vários séculos têm invadido o seu território, estimula-se o autoconhecimento, a reaprendizagem das formas de relacionamento e coesão social próprias do mundo indígena. Estas reelaborações do pensamento, da palavra e do saber visam configurar espaços de harmonia e bem-estar e são constituidoras de epistemologias próprias, (SANTOS, 2011), diferentes das impostas pela universalização eurocêntrica da lógica da colonialidade, do cristianismo e do capital.

\section{Caminho metodológico}

Os dados apresentados neste artigo provêm da produção intelectual do Movimento Indígena Nasa e dos trabalhos publicados nos últimos quarenta anos por antropólogos, historiadores e ativistas sociais vinculados a ele. $\mathrm{O}$ texto se alinha com a perspectiva de pesquisa qualitativa e bibliográfica, que de acordo com Oliveira (2012), possibilita investigar os fenômenos de maneira incisiva ao ampliar a compreensão de dados espaço-temporais dispersos.

Este artigo se desprende da dissertação de mestrado "Comunidade Indígena Nasa da Colômbia: um projeto político e educacional com base na luta histórica pelo território, a cultura e a autonomia", apresentada e aprovada em 2019 no Programa de Pós-graduação em Educação da Universidade do Estado de Mato Grosso UNEMAT, na linha de pesquisa Cultura e Diversidade. 


\section{Dialogia}

MENDOZA, Fabian; OLIVEIRA, Rosângela Pereira de. Comunidade Indígena Nasa: Gênese histórica da construção de uma pedagogia própria

\section{Gênese histórica da construção de uma pedagogia própria}

\section{1 "La Cacica la Gaitana” - 1537. A primeira "Minga de Resistência”}

Antes de retroceder cinco séculos à época da invasão militar espanhola no continente americano, seria preciso esclarecer o que é uma "Minga", e em particular, o que é uma "Minga de Resistência”. A “Minga”, em primeiro lugar, é a prática de associação solidária para o trabalho, um aspecto essencial da cultura e da vida comunitária dos povos andinos, similar ao conceito de mutirão do Movimento dos Trabalhadores Rurais sem Terra do Brasil - MST. Significa, portanto, reunião para qualquer trabalho coletivo.

Também é uma experiência de ensino-aprendizagem conjunta, um espaço pedagógico e formativo solidário onde se partilha pensamento e palavra, se discutem os problemas da comunidade e se determinam as ações derivadas dele. Nas "Mingas" se confere mais relevância ao encontro, ao contato e à coesão entre as pessoas que ao produto mesmo do trabalho. É, em suma, uma antiga tradição de educação popular não escolarizada dos povos indígenas.

Uma "Minga de Resistência" é a mobilização massiva de milhares de pessoas com um objetivo específico, pelo geral, ganhar visibilidade e convidar aos não indígenas para refletir diante de um problema que afeta a todos. Trata-se de um mecanismo de pressão política e social que revela uma enorme capacidade organizativa e logística para assegurar sua permanência de maneira indefinida.

As "Mingas de Resistência" se originaram no século XVI durante a ocupação militar do continente pelos europeus na procura de minas de ouro e prata. Essa busca determinou o controle dos territórios e a escravidão dos indígenas. Sebastián de Belalcázar foi um dos personagens mais relevantes nesse processo, participou da vitória que desmantelou a parte norte do império incaico, recebeu da Coroa espanhola o título de "Adelantado" e fundou as cidades de Quito, Guayaquil, Bogotá, Popayán e Cali.

É no contexto da invasão e ocupação dos territórios circunvizinhos a estas duas últimas fundações de Belalcázar que ele e seus homens entram em guerra com uma confederação de diversos povos indígenas do sul da Colômbia, entre eles, os Nasa. E é no meio dos acontecimentos relativos à primeira guerra entre espanhóis e Nasas, de 1536 a 1541, que emerge esta figura axial da resistência indígena, “la Cacica La Gaitana”. Uma mulher.

Sua história, seu mito, conservam-se, com algumas variações, na memória coletiva do povo e nas suas tradições orais até hoje. Conta-se que um jovem indígena chamado Boiponga 
ou Güiponga, chefe de algum daqueles clãs indígenas escravizados, indignado por ver seu povo chicoteados e acorrentado por estrangeiros, não quis comparecer ao encontro previsto por Añazco, um dos capitães de Belalcázar, para assentir as novas obrigações dos indígenas como súditos e tributários do Rei.

O espanhol, observando o descumprimento a suas ordens, mandou trazer o moço, e, num ato exemplar, ordenou que fosse queimado vivo na presença da multidão. Foram inúteis os protestos da comunidade e as lágrimas e súplicas de Guaitipán, a mãe do moço. A ordem foi cumprida e esta mulher abandonou o local discretamente, sem ameaça, queixa ou choro.

Guaitipán, conhecida posteriormente como "La Gaitana”, organizou a primeira grande “Minga de Resistência” e inaugurou uma tradição metodológica e pedagógica sem imaginar sua abrangência e vitalidade até nossos dias. Empreendeu uma longa travessia indo de choça em choça, de tribo em tribo, de aldeia em aldeia, dialogando, conscientizando, convencendo e organizando ao povo para lutar contra o invasor.

Conseguiu a adesão de alguns caciques aliados dos espanhóis e com cinco mil indígenas rodeou o acampamento onde Pedro de Añazco e outros trinta espanhóis pernoitavam. O capitão espanhol foi capturado e levado vivo diante de La Gaitana. O mito diz que ela arrancou os olhos dele com suas próprias mãos, perfurou sua pele entre a boca e o queixo e lhe pôs um laço para levá-lo de aldeia em aldeia onde cada vez lhe era cortado um membro de seu corpo, até que morreu. A tradição fala que os pedaços do corpo do espanhol foram moídos, queimados, convertidos em cinza e jogados no rio Páez e que "La Gaitana” gritou: "Vai embora daqui, sai, vai para tua Espanha que mais te ver não precisamos" (JULIO NIQUINÁS, 1972, apud. RAPPAPORT, 2000, p. 206).

Desta maneira, os indígenas Nasa de hoje revivem o mito de "La Cacica La Gaitana" quando caminham a palavra, quer dizer, quando se encontram, reúnem seus pensamentos e conhecimentos e empreendem essas massivas marchas pelas estradas da Colômbia para chamar a atenção dos poderes centrais e convidar ao país inteiro a refletir sobre sua grave situação. Assim são as "Mingas de Resistência” hoje, um espaço onde confluem além de várias comunidades indígenas, organizações de camponeses, afrodescendentes, estudantes e trabalhadores.

Depois dos acontecimentos de "La Cacica La Gaitana", vieram mais duas grandes guerras contra a resistência indígena nos Andes colombianos. A segunda entre 1561 e 1571, e a terceira entre 1595 e 1650, depois das quais a população nativa praticamente desapareceu 
daqueles territórios. Contudo, os escassos sobreviventes, na sua maioria mulheres, guardaram na memória e na palavra as lições do acontecido.

\section{2 "Juan Tama de la Estrella"- 1698. Conhecimento para recuperar o território sem armas}

Para essa época a população nativa começava a se recuperar depois de seu quase extermínio. Contudo, religião, idioma e costumes europeus, (vestimenta, alimentação), iam sendo cada vez mais adotados pelos indígenas.

Em finais do século XVII apareceu uma série de novos caciques capazes de compreender a viabilidade de unificar o território por meio de uma estratégia jurídica original. Primeiro, fortaleceram sua autoridade seguindo os ensinamentos herdados de "La Cacica La Gaitana", e exibiram grande habilidade política para dialogar e gerar consensos entre os diversos grupos étnicos da região. Além disso, eram bilíngues e sabiam ler, o que lhes permitia ter acesso à legislação dos brancos.

O cacique Juan Tama de la Estrella continuou com o labor de seus predecessores, transmitindo um novo ensinamento a seu povo: a investigação. Assim, empreendeu uma imersão nas leis do império espanhol e fez uma leitura crítica que detectasse seus vazios. $\mathrm{O}$ resultado dessa revisão foi a descoberta das disposições que amparavam o direito dos indígenas a reclamar e legitimar a propriedade coletiva de seus territórios. Em consequência, redigiu, na língua formal das instituições espanholas, um recurso escrito com a sustentação jurídica necessária para efetivar suas demandas que levou pessoalmente à Real Audiência de Quito. Tempos mais tarde o Rei da Espanha concedia e entregava os títulos de propriedade coletiva de seus territórios aos indígenas Nasa, em mãos de seu cacique.

Por isso é a figura mais importante da história dos Nasa, pois modificou o sentido de sua luta e resistência, realizada antes pelas armas e com precários resultados. A partir dele a pesquisa, o estudo, o conhecimento se converteram em instrumentos de vital importância para a resistência. Finalmente, percorreu as aldeias de seu território ensinando aos indígenas o significado dessa conquista, um esforço pedagógico onde ecoam os passos de "La Gaitana".

Essa vitória permitiu iniciar a recuperação do território, da identidade e da cultura Nasa, motivo pelo qual é considerado sábio, mestre, guia, defensor, intercessor, inspirador e pedagogo. Antes de morrer o cacique deixou formulada no seu testamento uma série de pautas morais com efeitos políticos e educacionais, com o fim de orientar a agenda política do presente 
e futuro. Estas disposições foram conhecidas, aprendidas e transmitidas por meio da tradição oral:

- A dinastia Tama-Calambás seguirá governando aos Nasa.

- O território dos Nasa será sempre próprio, impedir-se-á que fique em mãos estranhas.

- Os Nasa não misturarão seu sangue com o dos outros.

- Os Nasa não poderão ser vencidos. (BONILLA, 2014)

O quarto enunciado parece a consequência da observância das três primeiras orientações. A sucessão dinástica da primeira das pautas estava ligada à posse dos títulos de propriedade coletiva, cuja proteção passaria a formar parte das responsabilidades de seus descendentes. O cuidado desses papéis era de suma importância, devido à corrupção da burocracia colonial que fazia sumir os arquivos das instituições locais para favorecer às famílias mais poderosas de Popayán.

A segunda implica a mobilização da comunidade por meio das "Mingas" a causa das repetidas tentativas de invasão do território. Para efetivar sua defesa seria necessária a continuação do trabalho pedagógico iniciado por ele.

A terceira orientação proíbe a união matrimonial com brancos, pois o ingresso da cultura do dominador no território acabaria diluindo os valores indígenas em reconstrução. A proibição não se refere a outras comunidades indígenas, já que na época do próprio Juan Tama o território dos Nasa albergava uma população multiétnica em processo de unificação linguística e cultural por meio de enlaces matrimoniais interétnicos.

Juan Tama aplicou metodologias ancestrais e inovadoras para conceber sistemas de proteção e difusão de conhecimentos fundamentais que consolidassem a resistência e possibilitassem obter outras metas, (autonomia e cultura própria). O cacique realizou um trabalho educativo e político de decolonização do ser, do saber e do poder (WALSH, 2013). Assim, em sua ação política e pedagógica estão as bases do futuro Projeto de Educação Própria do povo Nasa.

\subsection{Manuel Quintín Lame - 1915. Reencontro com a identidade e a unidade indígena}

Quase dois séculos depois de Juan Tama emerge a figura de Manuel Quintín Lame. A república liberal colapsa no meio de infindáveis guerras civis onde os representantes armados das diversas elites regionais disputam o controle do governo nacional. A situação dos indígenas piora, seus territórios são usurpados pelo mercado e as monoculturas, seus títulos de 
propriedade coletiva são desconsiderados pelas leis do Estado e sua força de trabalho é explorada pelos fazendeiros da região.

Quintín Lame é um indígena que não fala a língua de seus ancestrais e que provém de uma família de indígenas camponeses sem terra. Viajando como soldado do exército colombiano aprende a ler e escrever e descobre a realidade dos indígenas e camponeses de seu país.

Quando regressa ao Cauca começa a assessorar juridicamente aos indígenas nas suas reclamações por terra e trabalho justo, o que lhe permitiu dimensionar a gravidade de sua miséria. Pouco tempo depois incita publicamente à recusa do pagamento do tributo de servidão exigido pelos fazendeiros. Assim, descobre a importância do processo investigativo para articular seu futuro projeto pedagógico, utilizando uma metodologia similar à desenvolvida por Juan Tama, entrando nos arquivos públicos e recuperando documentos que confirmassem os "limites territoriais das comunidades que pretendia reconstruir", (ESPINOSA, 2003, p. 158).

Dessa maneira Quintín Lame identificou os estragos do analfabetismo, e entendeu que sua missão era educar as comunidades para serem conscientes deste prejuízo. Três aspectos articulavam seu projeto educativo: conhecer a legislação, alfabetizar e investigar no pensamento histórico indígena.

Sua atividade pedagógica, ainda que acusada de subversiva, começou da mesma forma que La Cacica La Gaitana e Juan Tama, quer dizer, nos encontros comunitários, nas “Mingas” de pensamento onde o letramento e formação política confluíam.

Nestas “Mingas” Quintín Lame explicava aos ali reunidos a natureza do sistema que os explorava laboral e economicamente e ao mesmo tempo aprofundava nas possibilidades de restituição de seus direitos por via legal. Era um orador único, considerado por seus seguidores um profeta, um mestre que reivindicava a terra, a liberdade e a alma indígena, (FINDJI e ROJAS, 1984). Foi capaz de integrar no seu discurso os símbolos e imagens da cosmovisão e da religiosidade popular, a compreensão da natureza e suas próprias reinterpretações da história, (RAPPAPORT 2000), criando uma narrativa de exaltação e empoderamento da identidade indígena.

Seu esforço de anos de investigação, leitura, produção de textos, pedagogia, discussão pública das problemáticas nas "Mingas" e reorganização das comunidades indígenas do Cauca, desembocou entre 1910 e 1920 no surgimento de um movimento de insurreição multiétnico (Nasa, Misak, Coconucos, e outros indígenas dos departamentos de Tolima e Huila), conhecido como "La Quintinada". 


\section{Dialogia}

MENDOZA, Fabian; OLIVEIRA, Rosângela Pereira de. Comunidade Indígena Nasa: Gênese histórica da construção de uma pedagogia própria

Este levantamento popular apresentou suas demandas no debate nacional pela primeira vez. Exigia-se a liberação de todos os indígenas do pagamento de qualquer tributação pessoal, defesa do território em contra das tentativas de fragmentação, consolidação do "Cabildo" indígena como centro de autoridade e organização política, recuperação das terras usurpadas pelo latifúndio, rejeição dos títulos sem fundamento nos decretos reais, reafirmação dos valores culturais indígenas e rechaço à discriminação racial e cultural.

Depois de muitas concentrações, protestos e ocupação de terras de latifúndio, o movimento foi duramente reprimido e sufocado. Manuel Quintín Lame acabou preso em 1917 acusado de roubo, incitação à violência e rebelião. A repressão atiçada pela polícia, os fazendeiros, os partidos tradicionais e a Igreja sobre os indígenas nos anos imediatamente posteriores à Quintinada, explica a desativação dos protestos no Cauca. Quintín Lame, sofreu toda classe de perseguições, reiteradas prisões, desterros e expropriações. Nunca mais conseguiu voltar a sua terra natal.

Refugiou-se numa comunidade de camponeses descendentes de indígenas do município de "Ortega" no departamento de "Tolima”, distante uns 450 quilômetros do território Nasa. Aí teve o tempo para contribuir na organização e educação da comunidade. Criou escolas onde desenvolveu um projeto de educação indígena próprio, mas foram sistematicamente assaltadas, saqueadas e destruídas pelas autoridades locais que as considerava subversivas.

Durante seu desterro em Ortega redigiu "Os pensamentos do índio que se educou dentro das selvas Colombianas" (2004), onde recolhe a cosmovisão e sensibilidade do ser e do sentir indígena e aprofunda na experiência de autorreconhecimento cultural e identitária. Essa exaltação da identidade indígena era o contradiscurso dos relatos construídos pela elite intelectual e política do país, caracterizados pela invisibilização do mundo indígena e o ocultamento de suas realidades, condições que acabaram normalizando as práticas de humilhação e subalternidade que padecia.

No seu livro remarca o acento na diferença radical entre o indígena e o branco, chamando de hipocrisia o contraste entre seu progresso material e sua ruína moral. Para ele o homem branco era o predomínio de uma natureza negativa, o resultado da inversão dos valores do mundo (ESPINOSA, 2003), organizado por um ser sem respeito pela mãe natureza e seus irmãos. O índio, pelo contrário, devia afirmar sua recusa a se esquecer da sabedoria adquirida da natureza. Do diálogo com ela nasce a rebeldia ontológica e epistemológica dos indígenas.

Quintín Lame é um antecedente direto dos projetos de educação indígena na Colômbia pelo aprofundamento na cosmovisão, a formulação dos referentes para uma educação 


\section{Dialogia}

MENDOZA, Fabian; OLIVEIRA, Rosângela Pereira de. Comunidade Indígena Nasa: Gênese histórica da construção de uma pedagogia própria

diferenciada (ROMERO, 2004), e sua iniciativa para empreender métodos investigativos do pensamento e da política indígena, revisitando a estratégia dos antigos caciques.

De igual maneira, sua proposta de fazer uma leitura crítica da cultura hegemônica e da indígena, adotando estratégias das duas fontes para enfrentar os desafios políticos e educacionais, preanuncia a aproximação intercultural do projeto de educação indígena implementado mais tarde pelo CRIC.

\section{4 "Consejo Regional Indígena del Cauca” - CRIC - 1971. A consolidação da organização indígena e seu projeto educacional}

O “Consejo Regional Indígena del Cauca” CRIC é uma confederação de "cabildos”, (corporações municipais ao interior dos territórios indígenas), surgida da aliança interétnica entre Nasas, Misak e Totoroes, comunidades nativas do departamento do Cauca, na perspectiva de resolver os seus problemas históricos de opressão econômica, política e cultural.

Naquela época a aliança entre o governo, a Igreja e os latifundiários continuava sendo a principal inimiga dos indígenas e sua situação de exclusão, discriminação e desterritorialização não mudara desde os tempos da "Quintinada".

Do ponto de vista educacional, o CRIC entendeu a necessidade de pôr em funcionamento um sistema educativo autônomo que transmitisse os valores políticos, históricos e culturais dos Nasa e das outras etnias, recolhendo todas as experiências pedagógicas anteriores com o propósito de oferecer sustentabilidade, no longo prazo, a luta pelo território e a cultura.

Muitos dos intuitos e metodologias desta organização são resultado de seus processos de investigação na história indígena. O sentido das "Mingas" como espaços de formação do pensamento, a palavra e a ação comunitária, seguindo o exemplo de "La Cacica La Gaitana"; a divulgação da legislação para exigir o devido respeito a seus direitos a partir de uma base jurídica sólida, como Juan Tama e Quintín Lame fizeram; a importância do trabalho interétnico e intercultural e a recuperação de língua e cosmovisão. Estes foram os objetivos do projeto político e educacional no surgimento da organização em 1971.

A investigação deu como resultado a produção de vários documentos que resgatam a memória dos indígenas do Cauca nos últimos cinco séculos, fundamento histórico de sua busca de autonomia. Assim, a história, o uso e apropriação dela, tornou-se a base da reconstrução de sua identidade étnica, (PEÑARANDA, 2015). Nada disso teria sido possível sem os 
historiadores locais, anciões e líderes comunitários portadores da memória e da palavra das lutas anteriores.

A retomada do controle de instituições tradicionais de governo indígena como os “Cabildos” se cumpria simultaneamente aos processos de recuperação de terras e consolidação pedagógica, prática em espaços não formais que progressivamente se formalizaria por meio da redefinição do papel da escola dentro da comunidade.

Isto significou desaprender algumas das marcas deixadas pela colonialidade do Estado e da Igreja e, em lugar delas, aprender a apreender, vivendo, lutando e escutando aos mais velhos acerca do significado da identidade em contextos de resistência. Ganhava importância para a vida do conjunto espaço-sociedade o conhecimento racional, emocional, espiritual e sensitivo da natureza e de si mesmos, como já ensinara Quintín Lame.

A prática pedagógica realizada em espaços de encontro comunitário, congressos, assembleias, oficinas, "mingas", revelava a presença de saberes "ocultos", de formas de pensamento e conhecimento próprias da ancestralidade. Descobria-se a legitimidade de libertar a cultura e a Terra, transpareciam os princípios de uma cosmovisão que a considera mãe e ser vivente. A educação para o autoconhecimento e revitalização dos saberes ancestralmente construídos faz surgir o reencontro com uma epistemologia guardada na voz e idioma indígenas, veículos para um mundo recobrado.

Pensava-se numa educação que fosse crítica dos valores que tinham demolido a dignidade dos indígenas, sem embaraço do caráter político de seus métodos e objetivos nem do afastamento da educação ministrada pela Igreja, mecanismo validador dos sistemas hegemônicos que desprezava a cultura indígena. A consolidação das escolas por e para o movimento indígena acarretava a ressignificação de seu conceito tradicional.

O Projeto de Educação Bilingue Intercultural - PEBI, vigente até hoje, nasce em 1978 orientado pelos seguintes critérios:

- Priorizar os ensinamentos dados com o exemplo. Os espaços de aprendizagem não estão limitados ao âmbito escolar. Aprende-se da vida, da natureza, do trabalho, da história, dos heróis da comunidade relatada pelos mais velhos, dos mitos. Aprende-se nas "mingas" e da família que também participa na configuração curricular da escola.

- As escolas devem ser o fundamento para a recuperação de terras e a reivindicação de outros direitos. A libertação da mãe terra ressignifica política, ética e culturalmente a luta pelo território. 
- Os professores devem ser selecionados pelas próprias comunidades.

- Devem ser bilíngues e estar dispostos a recuperar a língua autóctone.

- As escolas devem ser viveiros para a revitalização da cultura.

- A comunidade deve participar na orientação das atividades escolares.

- A escola deve ser crítica do mundo exterior e da própria comunidade.

- As crianças devem ser encaminhadas a ficar nas suas comunidades e servir a elas.

- É necessário construir coletivamente o currículo e prescindir dos planos curriculares do Estado.

- As aulas devem ser ministradas em nasa-yuwe e castelhano.

A anterior síntese histórica pretende evidenciar de que forma resistência, cultura, ancestralidade, cosmovisão, memória, identidade e território se integram para construir um projeto próprio e original de educação. O seu sentido é restaurar e revitalizar a relação humanoterritório, conexão fraturada por vários séculos de submissão cultural, política e econômica a poderes externos. $\mathrm{O}$ fato de que esse projeto se conheça pelos não indígenas, na Colômbia onde é escassamente reconhecido e em outros países, pode insinuar os caminhos de uma educação para a harmonização com a natureza e a dignidade humana.

\section{Considerações finais}

Os programas de educação do povo Nasa são projetos em andamento, em construção, pois a educação é também um território em disputa com o Estado colombiano, que ainda insiste em relacionar as organizações indígenas com agrupações subversivas. Contudo, a prática rigorosa da não violência tem fortalecido nos últimos anos ao movimento indígena colombiano, ganhando legitimidade e reconhecimento entre vários setores, camponeses, estudantes, trabalhadores, ecologistas, mulheres, que se solidarizam e identificam em consciência e em ação com suas reivindicações.

Essa longa história ligada ao território e a luta por ele, é o elemento central de todas as construções culturais do povo Nasa e a razão da sua abrangência. A criatividade e a flexibilidade do pensamento indígena para adotar, transformar e reinventar algumas das noções monolíticas da sociedade majoritária, (cultura, história, identidade), dialoga com outros movimentos e comunidades ancestrais do continente e lhes brinda perspectivas de reflexão e ação. 
A centralidade nos processos educacionais de cosmovisão, tradição oral e interculturalidade são a base da luta pela libertação da mãe terra, desmitificando assim uma suposta belicosidade para a concretização de seus objetivos políticos.

A vida e as histórias de "La Cacica la Gaitana”, Juan Tama e Manuel Quintín Lame, guardam o potencial para inspirar as lutas nos momentos mais difíceis que atravessa esta comunidade. Nelas se alicerça um projeto educacional comprometido em criar uma cultura de paz na Colômbia, país golpeado historicamente pela naturalização das desigualdades e injustiças geradoras de novas violências.

O CRIC e suas iniciativas educativas, demonstram que é possível organizar e construir projetos no longo prazo edificando-os a partir do povo, dos anciões, das mulheres, do pensamento delas e deles, de sua palavra e experiência, que, ainda que possa parecer simples, é a própria, é a deles.

\section{Referências}

BONILLA, V. Historia política del pueblo Nasa. Popayán: Asociación de Cabildos Indígenas del Norte del Cauca-ACIN, 2014.

DUSSEL, E. 1492 El Encubrimiento del Otro: hacia el origen del "mito de la Modernidad". La Paz: Plural Editores, 1994.

ESPINOSA, A, M. El indio lobo. Manuel Quintín Lame en la Colombia moderna. Bogotá: Revista Colombiana de Antropología, Volumen 39, enero-diciembre 2003, p. 139-172.

FINDJ, M; ROJAS, J. Territorio, economía y sociedad Páez. Cali: Universidad del Valle, 1984.

LAME, M, Q. Los pensamientos del indio que se educó dentro de las selvas colombianas. Em: Cristóbal Gnecco (editor), Los pensamientos del indio que se educó dentro de las selvas colombianas. Cali: Editorial Universidad del Cauca y Facultad de Humanidades de la Universidad del Valle, 2004, pp. 139-249.

MIGNOLO, W. La idea de América Latina: la herida colonial y la opción decolonial. Barcelona: Gedisa, 2007.

OLIVEIRA, M, I. Guia Prático: Projetos de pesquisa e Trabalho Monográfico. Cáceres, Ed. UNEMAT, 2012.

PEÑARANDA, D. Guerra propia, guerra ajena. Conflictos armados y reconstrucción identitaria en los Andes colombianos. El movimiento armado Quintín Lame. Bogotá: CNMHIEPRI, 2015. 


\section{Dialogia}

MENDOZA, Fabian; OLIVEIRA, Rosângela Pereira de. Comunidade Indígena Nasa: Gênese histórica da construção de uma pedagogia própria

PORTELA, H. El arco, el cuerpo y la seña: Cosmovisión de la salud en la cultura Nasa. Popayán: Universidad del Cauca, 2018.

RAPPAPORT, J. La política de la memoria: interpretación Indígena de la historia en los Andes colombianos. Popayán: Universidad del Cauca. 2000.

ROMERO, F. Aspectos pedagógicos y filosóficos en Los pensamientos del indio que se educó dentro de las selvas colombianas de Manuel Quintín Lame. In: Cristóbal Gnecco (editor), Los pensamientos del indio que se educó dentro de las selvas colombianas. Cali: Editorial Universidad del Cauca y Facultad de Humanidades de la Universidad del Valle, 2004, p. 111138.

SANTOS, B, S. Epistemologías del Sur. Disponível em:

http://www.boaventuradesousasantos.pt/media/EpistemologiasDelSur_Utopia\%20y\% 20Praxis\%20Latinoamericana_2011

WALSH, C. (ed.). Pedagogías decoloniales. Prácticas insurgentes de resistir, (re)existir y (re)vivir. Quito: Ediciones Abya-Yala, 2013. 